\title{
IDENTIDAD Y HEGEMONÍA: TIMES SQUARE Y LA PRODUCCIÓN AMATEUR
}

\author{
José Luis Ortega Lisbona \\ Universitat Politècnica de València, Dpto. Escultura
}

Resumen

Si pensamos en la relación del espacio urbano contemporáneo con la luz, debemos hablar de dinámicas sociales dentro de las metrópolis contemporáneas y de cómo estos suponen un paradigma de la transformación tecnológica y social respecto a los media dentro del espacio urbano. Esto ha culminado con la conversión de las pantallas basadas en tecnología LCD en parte del medio en el cual nos desenvolvemos socialmente mediante las redes sociales. Por otro lado el lugar se diluye dentro de imágenes virtuales, dislocadas y descontextualizadas, convirtiendo la ciudad en un interfaz comunicativo, y lo visual en una experiencia espacial. Es por ello que es de especial interés analizar este fenómeno en el cual entran en juego elementos que afectan a los marcos constitutivos de nuestras experiencias sociales e identitarias dentro de un espacio variable y contingente, gracias al cual se está produciendo un desplazamiento de los usos dentro de la esfera pública, generando nuevas formas de espectáculo que producen nuevas políticas de vigilancia del otro.

\section{Palabras-clave: TIMES SQUARE; IDENTIDAD; REDES SOCIALES; PANTALLAS URBANAS; ESPACIO PÚBLICO}

\section{IDENTITY AND HEGEMONY: TIMES SQUARE AND THE AMATEUR PRODUCTION}

\begin{abstract}
If we think about the relationship of contemporary urban space and light, we must talk about social dynamics within contemporary cities and how these represent a paradigm of technological and social transformation with respect to the media in the urban space. This has culminated in the conversion of LCD technology screens into part on the environment in which we operate through social networks. On the other hand the place is diluted into virtual images, dislocated and decontextualized, turning the city into a communicative interface, and the visual in a spatial experience. That's why it's especially interesting to analyze this phenomenon in which elements come into play affecting the constituent frames of our social experience and identity in a variable and contingent space, through which it is producing a shift of uses within public sphere, creating new forms of entertainment that produce new surveillance policies of the other.
\end{abstract}

Keywords: TIMES SQUARE; IDENTITY; SOCIAL NETWORKS; URBAN SCREENS; PUBLIC SPACE.

\footnotetext{
Ortega Lisbona, José Luis. 2016. “Identidad y hegemonía: Times Square y la producción amateur”. AusArt 4(1): pp-pp. 155-163 D0I: 10.1387/ ausart.16694
}

\section{AUSART}


Uno de los conceptos más importantes de la realidad contemporánea es la manera en la cual la economía ha invadido todas las facetas de las áreas humanas, reduciendo lo social a un hecho que se articula a través de la economía. Este hecho es sustentado por el avance tecnológico respecto a los flujos de información mediante la conectividad electrónica, dando lugar a lo que William J. Mitchel denomina "ciudad en red" $(2001,27)$. Una ciudad que es fruto de lo que se ha venido a denominar economía global, y en la cual los media y las comunicaciones electrónicas soportan y sustentan un desarrollo económico caracterizado por los constantes e instantáneos movimientos de capitales que sustentan el capitalismo global.

Esta tipo de urbe caracterizada por la simultaneidad de elementos físicos y virtuales, que se complementan a la hora de conformar un nuevo tipo de paisaje constituido por datos, adquiriere una configuración que produce una ruptura con los modelos anteriores de ciudad. Estos datos son instrumentalizados para conformar el rumbo de la economía mundial y las más importantes estructuras de telecomunicaciones, dando lugar a lo que el mismo Mitchell se refiere como "city of bits", donde gran parte de las actividades económicas, sociales y culturales que antes tenían lugar en la ciudad ahora se llevan a cabo en el ciberespacio, de manera que no responden a ningún lugar geográfico, estableciendo un dominio del software sobre la forma material. La tecnología digital esta transformando la arquitectura tradicional debido a la influencia del ciberespacio en el mundo físico. Los espacios de internet se presentan como una metáfora de la ciudad en su aspectos sociales y económicos, los cuales por otro lado se presentan en gran medida hibridados.

Si nos disponemos a estudiar la relación entre los nuevos modos de vida desarrollados dentro de la urbe contemporánea y las tecnologías de la imagen dentro de estos espacios, podemos pensar sobre lugares que forman parte del imaginario colectivo. Este es el caso de Times Square, lugar mediatizado por excelencia y marco perfecto para investigar las relaciones existentes entre mass media, identidad y redes sociales.

En esta esfera pública se unen la imagen, la tecnología y el espacio público, este último entendido como una esfera social y un lugar de debate y participación de todos los ciudadanos. Por lo tanto es a todas luces imprescindible elaborar una nueva etnografía de la esfera pública teniendo en cuenta las nuevas implicaciones que la imagen, las redes y la multitud interconectada han supuesto para nuestra experiencia en el espacio público. Los nuevos tipos de relación desarrollados en este tipo de espacios mediatizados nos hace 
preguntarnos: ¿qué mecanismos articulan los vínculos que las personas establecen en este espacio público?

Paul Virilio nos habla de una aceleración vinculada a las tecnologías de la imagen. Estas han provocado un enajenado viaje hacia las geografías virtuales que carecen de fronteras establecidas, en cuanto a su función como medio de transmisión de información, que ha conseguido desvincular el poder del territorio, generando un gran numero de espacios que operan de manera transnacional e inmaterial. En su obra The Lost Dimension, Virilio denomina "ciudad sobreexpuesta" a una urbe cuyo aspecto es continuamente reconstruido por la aparición de pantallas electrónicas ([1983] 1991,33).

El desarrollo de multitud de interfaces ha producido también que nuestra vida desarrollada en el exterior también queda registrada, deviniendo nosotros mismos una imagen por voluntad propia. Todo esto pone de manifiesto un desplazamiento de los usos que anteriormente se atribuían al espacio público hacia el ámbito virtual de la esfera pública, gracias a la producción de una serie de prótesis virtuales que nos posibilitan ejercer como administradores de nuestro propio espacio simbólico virtual desmaterializado, generando paradójicamente un concepto de lo real que no tiene que coincidir necesariamente con la realidad, en la cual nuestros símbolos ya no se encuentran en la realidad física, como sucedía anteriormente mediante el lugar antropológico antes citado, sino en la que construimos diariamente en la red.

A la hora de analizar este nuevo espacio público contemporáneo podemos optar por varias metodologías de investigación que aportan un cariz antropológico a nuestro visión de lo urbano. La "observación flotante" surge a principios de los 80 como respuesta a una esfera pública contemporánea en la cual la movilidad de las relaciones sociales y la fugacidad del tránsito de los actores del espacio urbano, han sido las señas de identidad, asentadas en una nueva ciudad caracterizada por la fluidez, el movimiento y el intercambio. Colette Pétonnete en su obra L'observation flottante $(1982,56)$ asentó las bases de una metodología a partir de esta nueva realidad urbana. Tiene como principal objetivo la producción de una mirada que no está fija en ningún punto en concreto, sino que permanece levitando sobre el espacio de manera que facilite el hallazgo de pautas o patrones que sirvan de punto de partida en la investigación. Este tipo de observación está diseñada para imposibilitar la aparición de prejuicios o ideas prefijadas que actúen sobre nuestra percepción distorsionando nuestro juicio, poniendo en valor nuestra propia experiencia en el estudio de los espacios. Manuel Delgado por su parte, profesor de la Universidad 
de Barcelona, nos habla de lo intangible y difícil de contener de la relaciones que intentamos analizar dentro de la urbe, debido sobre todo a lo líquido de los ejes que organizan nuestra vida social $(1999,46)$. No contamos en muchos casos con instituciones estables, sino que tratamos con lo instantáneo. Por consiguiente, al analizar nuestro estatus dentro de un espacio, nos encontramos situados dentro de "todo lo que en una ciudad puede ser visto flotando en superficie", con lo cual podemos hablar del aspecto contextual de la identidad del transeúnte y de la imposibilidad de formar una identidad colectiva debido a lo fluido y lo transitorio de nuestro estatus, entendiendo lo urbano como un espacio en el cual somos licuados y disueltos constantemente. Es por ello que esta situación es perfecta para desarrollar nuestra labor como etnógrafos de lo urbano, como un moderno narrador de la novela de Edgar Allan Poe El hombre de la multitud (Poe, 1840), en la cual dicho personaje observa pasar, desde un café londinense, a todo tipo de viandantes, realizando un análisis pormenorizado de cada uno de ellos.

La plaza de Times Square está conformada por la intersección de Broadway con la $7^{\mathrm{a}}$ Avenida, siendo un lugar clave de confluencia dentro de la urbe. Como podemos observar a simple vista, la plaza permanece de manera continua ocupada por una multitud de turistas, performers, visitantes ocasionales y todo tipo de individuos que deambulan por este lugar. La inmensa mayoría tienen como nexo en común la contemplación del fascinante espectáculo mediático en forma de pantallas que tiene lugar en la plaza.

Es aquí donde podemos empezar nuestro personal estudio adoptando el rol de observador-participante debido a nuestro estatus de ciudadano transitorio, siendo totalmente partícipes y a la vez voyeurs. Ser unos extraños es por lo tanto la garantía de nuestro éxito como observadores dentro de una multitud de extraños. Este rol de turista nos permite observar desde dentro sin ser percibido como un intruso, siendo testigo de las interacciones que tienen lugar ante nuestros ojos. Por lo tanto, podemos mantenernos flotando sin imponerme ningún tipo de filtro, esperando, sin embargo, la aparición de patrones o puntos de referencia mediante los cuales comenzar nuestro análisis como naturalistas de lo urbano.

Por otro lado, mediante la toma de material fotográfico podemos generar todo un catálogo de hechos aislados que tienen lugar a diario. Tomando como protagonistas a los ocupantes del lugar, podemos generar una narración fragmentada de lo que resulta llamativo y atrae al observador. Pasamos de lo abstracto y general de los viandantes como colectivo, a los detalles individua- 
les de cada uno. Este proceso de desfragmentación de la multitud nos puede llevar a realizar narraciones fragmentarias de esta experiencia mediante las nuevas formas de narración constituidas como producto mediático.

Esto nos puede llevar a enfocarnos exclusivamente en la producción amateur realizada a diario por los visitantes en las redes sociales como material mediante el cual reflexionar sobre la conceptualización de lo real, y la relación entre real y virtual. ¿Hasta qué punto no es todo este material una extensión de la propia experiencia en el espacio público y hasta qué punto es una experiencia real?

La recopilación de fragmentos de vida adquiere un carácter etnográfico tal y como nos cuenta Juan Martín Prada en su obra Otro tiempo para el arte (2010, 23). Lo podemos relacionar con la inmediatez y la fluidez de las experiencias, tanto reales como virtuales, dentro de la esfera pública contemporánea; y de la cual todos los ocupantes del lugar son partícipes. Este hecho nos lleva a descubrir la manera en la cual nuestra experiencia, dentro de un espacio, se extiende dentro de la esfera mediática como forma autobiográfica, pero también como construcción colectiva de la imagen de Times Square, la que por otro lado está físicamente constituida por una arquitectura mediada, en el sentido de que son los propios media mediante pantallas los que conforman las paredes del lugar.

Como ya en 1970 Marshall McLuhan nos anunciaba en su libro Take Today (McLuhan \& Nevitt 1972, 145), esto se encuadra como consecuencia del avance en la tecnología, el cual ofrece herramientas mediáticas de producción al alcance del público en general. También Manuel Castells en su obra La Galaxia Internet (2001, 51), nos habla sobre los nuevos "productores-usuarios" y cómo estos generan su propio relato dentro de la redes. En este punto, y gracias al modo de relación con el medio y sus ocupantes que la metodología propiciaba, podemos reflexionar sobre la posibilidad de crear una etnografía de un espacio público a través de su reflejo en la producción autobiográfica de los visitantes.

Podemos también por lo tanto, indagar dentro de la esfera mediática y, como Boris Groys (Groys, 2014, 120) nos sugiere, convertir la narración colectiva del lugar en una obra.

Esta producción, tal y como nos cuenta Gemma San Cornelio en su obra Arte e Identidad en Internet $(2008,18)$, está ligada al concepto de self branding 
o autopromoción, proponiendo nuestro actuar en la redes como un proyecto reflexivo del yo, el cual según nos cuenta Foucault ([1971] 1988, 153), es sin duda algo hecho o producido mediante la acción sobre uno mismo.

Qué mejor manera de tomar constancia de esta acción sobre nosotros mismos que el material de carácter autobiográfico que compartimos en las redes sociales. Este tipo de narraciones ponen de manifiesto lo hiperfragmentado de los materiales que creamos en la red, producidos en torno al movimiento y experiencias imbuidas por el espacio mediatizado. Como Guy nos cuenta en su obra La Sociedad del Espectáculo:

"El tiempo del consumo de imágenes, médium de todas las mercancías, es, inseparablemente, el terreno en donde se ejercen plenamente los instrumentos del espectáculo."

(Debord [1967] 1999, 136)

Por lo tanto, este lugar es el paradigma de espacio en el cual las imágenes son consumidas pero también en el cual se produce una gran cantidad de material, poniendo de manifiesto, de nuevo, el papel del consumidor-productor del que hablé anteriormente.

Este espacio se ha convertido en el epítome de la transformación de los medios en un tejido que cubre la urbe y la traducción de una experiencia social intangible y sensual en una forma urbana. Esta metamorfosis ha dado lugar a la transformación de la pantalla en una tipología de edificio. Virilio en Estética de la desaparición, describe la pantalla como el paso de algo material a algo que no lo es, explorando el concepto de desmaterialización en cuanto a la manera en la cual sirve como espacio, en el que se pierden las dimensiones espaciales y donde tiene lugar una transformación tecnológica del tiempo que nos hace olvidar nuestra situación material, una elipsis constante en nuestra consciencia desde nuestro estatus de espectadores de la ciudad ([1980] 1988, 58).

Los videos elaborados por los viandantes resultan ser, pese a su carácter inmaterial, productos industriales al igual que en su momento lo fue la famosa Fuente de Duchamp, solo que en este caso se trata de un producto elaborado dentro del ámbito de mediático de la industria cultural gracias a las nuevas aplicaciones de la web 2.0. Estas aplicaciones se valen del tiempo libre de la multitud para generar contenidos que hacen funcionar estos espacios en el campo relacional, pero también en el económico, generando grandes bene- 
ficios para las corporaciones transnacionales que están detrás de ellas. Por otro lado, este tipo de aplicaciones generan un comportamiento alienado y vehiculizado en los usuarios, haciéndoles bailar al son que se les marca, tal y como Natalie Bookchin nos muestra en su obra The Mass Ornament, en la cual mediante una videoinstalación genera una coreografía constituida por los videos amateurs de varios usuarios de Youtube que parecen bailar acompasadamente a un mismo ritmo de manera simultánea.

Esta relación de los ocupantes de Times Square y los media es realmente palpable, de hecho, el actual espacio público de Times Square se ha caracterizado durante su historia por la ocupación de diferentes media que han construido la narrativa colectiva del lugar, desembocando en el paradigma contemporáneo de arquitectura diluida dentro de un tejido mediático que recubre todos los edificios de este espacio. La propia configuración del espacio actual está concebida como un lugar de contemplación de este espectáculo mediático, produciendo una banalización del concepto de lugar para ligarla al espacio social del consumo en los momentos de ocio y vacaciones (Debord [1967] 1999, 144). Sin embargo, el desarrollo de la producción amateur en el ámbito mediático ha producido un cambio de paradigma de este lugar, en el cual ya no solo se asiste a una representación, sino que esta marea mediática es contestada por los usuarios en forma de producción de material autobiográfico que es publicado instantáneamente en las redes. Este material es perfecto para establecer un estudio etnográfico dentro de este espacio, pero también es de utilidad para generar una narración colectiva de este lugar.

Por otro lado este tipo de relatos han redefinido la conceptualización de lo que podemos considerar real dentro de los nuevos espacios virtuales. La construcción de un espacio simbólico en Internet mediante imágenes y videos que nos construyen frente a los demás, ha mutado, como nos cuenta Juan Martín Prada $(2013,53)$, el sentido mismo del término real, para concebirlo como el deseo de interconexión constante y la avidez comunicativa de la multitud interconectada. Ambas experiencias son reales, tanto la que tienen lugar en la plaza como la que tiene lugar en las redes. Más bien pertenecen a una experiencia conjunta e indisoluble. Esto resulta paradójico si tenemos en cuenta la desaparición de la arquitectura en Times Square dentro de una tejido mediático compuesto por pantallas de tecnología LED. De manera que, mientras los media hacen desaparecer la arquitectura, la multitud está más presente y activa que nunca dentro de estos, siendo a la vez receptores y productores de contenidos. Podríamos decir que este lugar ha mutado su función de lugar de encuentro; para pasar a ser un catalizador de los momentos de ocio que se 
constituyen como espacio de producción mediática, inspirada por el espectáculo de la arquitectura mediada circundante.

Podemos afirmar que este espacio resulta también realmente paradigmático en cuanto a la manera en la cual se desarrollan la nuevas dinámicas de construcción identitaria. La colisión que tiene lugar entre las imágenes del yo y las del otro tal y como Lacan nos cuenta en sus escritos ([1966] 2013, 45), está englobada dentro de la construcción que tiene lugar sobre nuestra imagen respecto a la de los demás en base al espacio y los media. Todo esto pone de manifiesto cómo la esfera mediática ha logrado imponerse hegemónicamente dentro del espacio público, no solo por la aparición de las pantallas ubicuas, sino por el uso que le damos al espacio, generando un nuevo tipo de prácticas sociales basadas en el conexión constante, y el uso de la imagen como interfaz comunicativo dentro de la producción mediática masiva. Todo esto pone de manifiesto un desplazamiento de los usos que anteriormente se atribuían al espacio público hacia el ámbito virtual de la esfera pública, gracias a la producción de una serie de prótesis virtuales que nos posibilitan ejercer como administradores de nuestro propio espacio simbólico virtual y desmaterializado. Por lo tanto nuestros símbolos ya no se encuentran en la realidad física, sino en la que construimos diariamente en la red. Este uso conforma una construcción colectiva del lugar presentándolo al mundo, pero también a los individuos que se construyen respecto a los demás usuarios mediante el actuar en las redes. Estas aplicaciones podrían considerarse conformadoras de una escultura social alienada, en el sentido de que vehiculizan la manera en la cual se expresa la multitud y nos lleva al un clímax del intercambio constante, como seña de identidad de la hegemonía de la cual Times Square es el ejemplo espacial más representativo de la cultura occidental.

\section{Referencias}

Baudrillard, Jean. 2006. La agonía del poder. Traducción de Marisa Pérez Colina y Ana C. Conde Madrid: Círculo de Bellas Artes

Groys, Boris. 2014. Volverse público: Las transformaciones del arte en el ágora contemporánea. Traducción, Paola Cortes Rocca. Buenos Aires: Caja Negra

Castells, Manuel. 2001. La galaxia Internet. Barcelona: Plaza \& Janés

Debord, Guy. (1967) 1999. La sociedad del espectáculo. Prólogo, traducción y notas de José Luis Pardo Madrid: Pre-Textos

Delgado Ruiz, Manuel. 1999. El animal público: Hacia una antropología de los espacios urbanos. Barcelona: Anagrama 
Foucault, Michel. (1971) 1988. Nietzsche, la Genealogía, la Historia. Traducción de José Vázquez Pérez. Valencia: Pre-Textos

Han, Byung-Chul. 2014. En el enjambre. Traducción de Raúl Gabás. Barcelona: Herder

Lacan, Jacques. (1966) 2013. Escritos I. Traducción del francés por Tomás Segovia y Armando Suárez. Madrid: Siglo XXI

Martín Prada, Juan. 2013. Otro tiempo para el arte: Cuestiones y comentarios sobre el arte actual. Valencia: Sendemá

McLuhan, Marshall \& Barrington Nevitt. 1972. Take today: The executive as dropout. New York: Harcourt Brace Jovanovich

Mitchell, William John. (1999) 2001. E-topía: Vida urbana, Jim, pero no la que nosotros conocemos. Traducción de Fernando Valderrama. Barcelona: Gustavo Gili

Pétonnete, Coclette. 1982. "L'observation flottante: L'exemple d'un cimetière parisien". "Etudes d'anthropologie urbaine", número monográfico de L'Homme, Revue Française d'Anthropologie 22(4): 37-47

Poe, Edgar Allan. (1975) 2010. Poe: Cuentos 1. Prólogo, traducción y notas de Julio Cortázar. Madrid: Alianza

San Cornelio, Gemma. 2008. Arte e Identidad en Internet. Barcelona: UOC

Virilio, Paul. (1980) 1988. Estética de la desaparición. Traducción de Noni Benegas. Barcelona: Anagrama

— (1983) 1991. The lost Dimension. Translated by Daniel Moshenberg. New York: Semiotexte

(Artículo recibido 06.04.16; aceptado 19.05.16) 